Portland State University

PDXScholar

\title{
An in Situ Experimental Study of Grain Growth in a Nanocrystalline Fe91Ni8Zr1 Alloy
}

\author{
Hasan Kotan \\ North Carolina State University \\ Kris A. Darling \\ Proving Ground \\ Mostafa Saber \\ Portland State University, msaber@pdx.edu \\ Ronald O. Scattergood \\ North Carolina State University \\ Carl C. Koch \\ North Carolina State University
}

U.S. Army Research Laboratory, Weapons and Materials Research Directorate, RDRL-WMM-F, Aberdeen

Follow this and additional works at: https://pdxscholar.library.pdx.edu/mengin_fac

Part of the Materials Science and Engineering Commons

Let us know how access to this document benefits you.

\section{Citation Details}

Kotan, H., Darling, K. A., Saber, M., Scattergood, R. O., \& Koch, C. C. (2013). An in situ experimental study of grain growth in a nanocrystalline Fe91Ni8Zr1 alloy. Journal of Materials Science, 48(5), 2251-2257.

This Article is brought to you for free and open access. It has been accepted for inclusion in Mechanical and Materials Engineering Faculty Publications and Presentations by an authorized administrator of PDXScholar. Please contact us if we can make this document more accessible: pdxscholar@pdx.edu. 


\title{
An in situ experimental study of grain growth in a nanocrystalline $\mathrm{Fe}_{91} \mathrm{Ni}_{8} \mathrm{Zr}_{1}$ alloy
}

\author{
Hasan Kotan - Kris A. Darling - Mostafa Saber • \\ Ronald O. Scattergood - Carl C. Koch
}

Received: 20 August 2012/ Accepted: 30 October 2012/Published online: 27 November 2012

(c) Springer Science+Business Media New York 2012

\begin{abstract}
Grain growth and microstructural evolution of thermally stabilized $\mathrm{Fe}_{91} \mathrm{Ni}_{8} \mathrm{Zr}_{1}$ were investigated by in situ and ex situ studies. Our investigations suggest that the microstructural evolution is fairly slow and the microstructure shows stabilization up to about $700{ }^{\circ} \mathrm{C}$. Above this temperature, a certain fraction of grains grow abnormally into the nanocrystalline matrix, resulting in a bimodal microstructure and causing the complete loss of thermal stability. The reason for abnormal grain growth and the loss of thermal stability is identified as the appearance of the fcc $\gamma$-phase and consequent reduction in the total area of grain boundaries and the overall stored energy.
\end{abstract}

\section{List of symbols}

$M \quad$ Grain boundary mobility

$Q \quad$ Activation energy

$v \quad$ Velocity of grain boundary

D Grain diameter

$h \quad$ Specimen thickness

$\delta \mathrm{D} \quad$ Incremental growth

$\delta G \quad$ Change in volume free energy

$\delta \Gamma_{s} \quad$ Change in surface energy

$\delta \Gamma_{\mathrm{i} / \mathrm{gb}}$ Change in the interphase energy-grain boundary energy

H. Kotan $(\varangle) \cdot$ M. Saber · R. O. Scattergood · C. C. Koch Department of Materials Science and Engineering, NC State University, 911 Partners Way, Room 3002, Raleigh,

NC 27695-7907, USA

e-mail: hkotan@ncsu.edu

K. A. Darling

U.S. Army Research Laboratory, Weapons and Materials Research Directorate, RDRL-WMM-F, Aberdeen Proving Ground, Aberdeen, MD 21005-5069, USA
$A_{s} \quad$ Free surface area

$A_{\mathrm{i}} \quad$ Grain interface area

$V \quad$ Volume of grains

$g \quad$ Bulk free energy per volume

$\Gamma_{s} \quad$ Surface energy per area

$\Gamma_{\mathrm{i}} \quad \boldsymbol{\alpha}$-to- $\gamma$ interface energy per area

$\Gamma_{\mathrm{gb}} \quad$ Grain boundary energy per area

$P \quad$ Pressure acting on the grain interfaces

$\tilde{D} \quad$ Diffusivity

$D_{o} \quad$ Frequency factor

$r \quad$ Diffusion distance

$t \quad$ Annealing time

$T \quad$ Annealing temperature

$R \quad$ Gas constant

\section{Introduction}

Nanostructured materials are promising for structural applications [1]. However, their widespread application is limited by an inherently high driving force for thermally induced grain growth, even at low temperatures [2-4]. Accordingly, the understanding of and control over grain growth in nanoscale materials is of great technological and scientific importance [5] as many physical properties (i.e., mechanical properties) are functions of the average grain size and the grain size distribution within the microstructure $[6,7]$.

In the last decade, extensive investigations into the stabilization of metallic nanocrystalline microstructures have been carried out to improve their stability. In spite of a high driving force for grain growth, significant stabilization has been reported [8-13]. This stabilization and resistance to grain growth has been attributed to reducing 
the energy of the grain boundaries with solute segregation (i.e., thermodynamic stabilization) [14] or reducing the mobility of the grain boundaries by grain boundary pinning (kinetic stabilization) [15]. Nevertheless, the reported works have, for the majority, been based on analysis of evolved microstructures post thermal processing, and not by direct observation at temperature. This is of fundamental importance as it is unclear how grain coarsening occurs in systems stabilized against growth. The advantage of in situ microstructural evolution studies comes from directly observing this phenomenon and its kinetics such that the respective mechanism and driving force can be understood in detail.

In this work, we used in situ transmission electron microscopy (TEM) with video imaging and in situ X-ray diffractometry (XRD) to directly follow grain growth and microstructural evolution in such a system as a function of temperature. Ex situ experiments are also reported giving a broader perspective of the microstructure at longer annealing times. The information obtained from these experiments enables the real time observation of microstructural evolution and phase transformation and provides a unique view of dynamic reactions as they occur.

\section{Experiments}

A ternary $\mathrm{Fe}_{91} \mathrm{Ni}_{8} \mathrm{Zr}_{1}$ alloy was chosen as the stabilized Fe-based nanocrystalline alloy for this study. As starting materials, appropriate masses of elemental $\mathrm{Fe}(99.9 \%), \mathrm{Ni}$ $(99.9 \%)$, and $\mathrm{Zr}(99.7 \%)$ powders were mixed with $440 \mathrm{C}$ stainless steel balls and sealed in a hardened steel vial under an argon atmosphere $\left(\mathrm{O}_{2}<2 \mathrm{ppm}\right)$ before milling. Ball milling was performed using a SPEX 8000 model mixer-mill for $20 \mathrm{~h}$. After milling, powders were isochronally annealed at $600,700,800$, and $900{ }^{\circ} \mathrm{C}$ in a $98 \%$ $\mathrm{Ar}+2 \% \mathrm{H}_{2}$ gas atmosphere for $1 \mathrm{~h}$ with subsequent cooling in the furnace where the cooling rate was less than $2-3{ }^{\circ} \mathrm{C}$ per second. The as-milled powder was used as the starting material for annealing at each temperature. Microstructure of the samples is characterized by focused ion beam channeling contrast imaging (FIB-CCI). FIB-CCI images were obtained using backscattered electrons produced by the ion beam from one powder particle.

The ion beam was also used to prepare an electron transparent sample from the as-milled powder for the in situ transmission electron microscopy (TEM) annealing experiments. The sample was mounted in the Aduro holder [16] and imaged in a Hitachi HF-2000 TEM. The Aduro system uses a flat, ceramic membrane as the active specimen support to enable fast, stable, and accurate thermal analysis. The membrane has a small thermal mass which allows for extremely fast heating rates up to $10^{6}{ }^{\circ} \mathrm{C} / \mathrm{s}$ with virtually instantaneous temperature stabilization and accuracy of $\pm 0.5-3{ }^{\circ} \mathrm{C}$. The whole experiment was recorded with a video imaging in bright field (BF) mode to directly observe grain growth in the initially nanocrystalline sample. The increment of the temperature was $50{ }^{\circ} \mathrm{C}$ during in situ annealing.

High temperature XRD analysis was carried out using an Anton Paar HTK 2000. Samples consisted of a thin layer of powder place onto a Pt strip. A given sample was then brought into alignment on the optical axis of the diffractometer. The heating chamber was pumped down, under a vacuum of approximately $10^{-3}$ Torr and backfilled with a He $3 \%$ hydrogen forming gas to prevent oxidation of the powders during examination. The sample was then resistively heated to temperature at a rate of $60{ }^{\circ} \mathrm{C} / \mathrm{min}$, at which point it endured a $10 \mathrm{~min}$ isothermal anneal, before performing a $17 \mathrm{~min}$ long diffraction scan at the respective temperature. The sample temperature was increased to the next desired set point and the isothermal/scanning process repeated as done previously. This process was repeated to cover the following temperature range of 30, 500, 600, 700, $750,800,900$, and again at $31^{\circ} \mathrm{C}$ to complete the test. The grain size at temperature was calculated by the Scherrer method.

\section{Results and discussion}

Figure 1 illustrates the morphological evolution of nanocrystalline $\mathrm{Fe}_{91} \mathrm{Ni}_{8} \mathrm{Zr}_{1}$ subjected to the in situ thermal annealing in the TEM up to $900{ }^{\circ} \mathrm{C}$. The snapshots were taken from the video and, in general, the majority of the observed grain growth ceased within the time frame given in Fig. 1. The real time monitoring of the microstructure during in situ thermal treatments revealed negligible grain growth until $500{ }^{\circ} \mathrm{C}$. Grain growth became discernible at $500{ }^{\circ} \mathrm{C}$ and all visible grains in the view remained smaller than $50 \mathrm{~nm}$ up to annealing to $600{ }^{\circ} \mathrm{C}$. Gradual increase of the average grain size (i.e., average grain diameter) is observed with the increase in temperature and a few grains reached the size of $100 \mathrm{~nm}$ after $15 \mathrm{~s}$ at $700{ }^{\circ} \mathrm{C}$. Above this temperature, a certain fraction of grains grew rapidly into the nanocrystalline matrix within the first few seconds of annealing, resulting in a bimodal microstructure at $750{ }^{\circ} \mathrm{C}$. Abnormal grain growth continued at the expense of their neighbors with the increase in temperature to 800 and $850{ }^{\circ} \mathrm{C}$. Further increase in annealing temperature to $900{ }^{\circ} \mathrm{C}$ caused the complete consumption of the smaller grains in the microstructure and led to normal grain growth where the microstructure exhibits a uniform increase in size. The last micrograph in Fig. 1 shows that grains in the viewing area are fairly uniform and reached the size of 

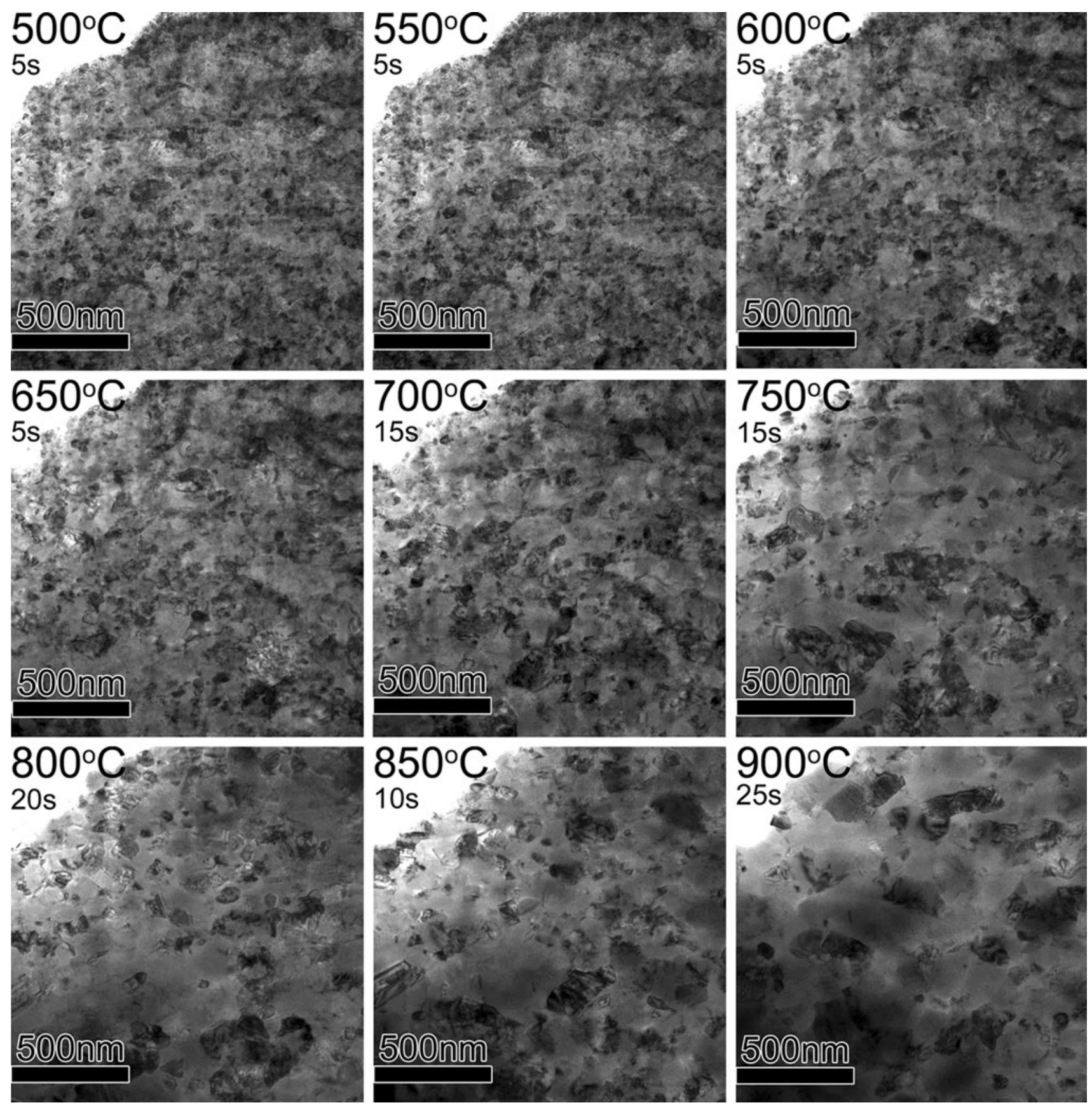

Fig. 1 Sequence of plan-view bright field TEM micrographs showing the morphological evolution of nanocrystalline $\mathrm{Fe}_{91} \mathrm{Ni}_{8} \mathrm{Zr}_{1}$ alloy during in situ thermal treatments. Below $700{ }^{\circ} \mathrm{C}$, the nanocrystalline microstructure remains stable. Above this temperature, a sudden abnormal grain growth is observed resulting in loss of thermal stability. All images are recorded at the same magnification. Temperature and the time at given temperature are displayed at the upper left corner of each micrograph
$400 \mathrm{~nm}$ after $25 \mathrm{~s}$ at $900{ }^{\circ} \mathrm{C}$, and the nanocrystalline microstructure is lost.

In addition to rapid and abnormal grain growth above $700{ }^{\circ} \mathrm{C}$, we also observed a loss of contrast between neighboring grains with the eventual disappearance of the grains or the boundary between them. The orientation of two grains has to be within a few degrees to appear in the same image. The fact that neighboring regions appear/ disappear suggests that these regions represent grains that have rotated into alignment with their neighbors to attain the orientation of one of its neighbors. The driving force for the grain rotation might arise from the tendency of the grains to reduce their overall grain boundary energy due to misorientations. This rotation of the adjoining grains is 
presumably required for crystallographic alignment before the subsequent merging of the two grains to attain the minimum crystallographic energy state [17].

In situ TEM observation indicated that microstructural changes and grain growth are fairly slow as the nanocrystalline state remains stable until $700{ }^{\circ} \mathrm{C}$. However, they become extremely fast especially for the first few seconds of annealing at above $750{ }^{\circ} \mathrm{C}$, resulting in sudden abnormal grain growth and loss of thermal stability. The view of the microstructure was limited in the in situ TEM experiment and the annealing time was rather short. We took advantage of ex situ annealing to investigate the microstructure subjected to longer annealing time and to eliminate the possible influences to grain growth by the free surfaces of the TEM sample. Figure 2 reveals low magnification FIB images of the as-milled specimen and annealed at 600, 700, 800 , and $900{ }^{\circ} \mathrm{C}$ for $1 \mathrm{~h}$. Upon comparison of the as-milled microstructure with samples annealed isochronally, we see that there is not a significant grain growth after $1 \mathrm{~h}$ annealing at $600{ }^{\circ} \mathrm{C}$. Above this temperature, at $700{ }^{\circ} \mathrm{C}$, a certain fraction of grains grow abnormally into the nanocrystalline matrix, resulting in a bimodal microstructure. That is, a few grains grew to above the nanoscale, greater than $100 \mathrm{~nm}$, while the majority of the microstructure remained nanoscale. The extent of abnormal grain growth continues to increase at $800{ }^{\circ} \mathrm{C}$, consuming the majority of the microstructure and leaving only a very small fraction of the microstructure nanocrystalline. Further increases in annealing temperature to $900{ }^{\circ} \mathrm{C}$ caused the complete consumption of the smaller grains (nano and ultrafine) in $\mathrm{Fe}_{91} \mathrm{Ni}_{8} \mathrm{Zr}_{1}$, which leads to the formation of a more uniform large grain assembly.

Consistent observation from ex situ FIB and in situ TEM results demonstrates that the majority of the nanocrystalline microstructure of the ternary alloy remains stable up to about $700{ }^{\circ} \mathrm{C}$ showing excellent thermal stabilization compared to reported examples of pure iron and $\mathrm{Fe}-\mathrm{Ni}$ alloys [18-21]. It is postulated that the grain growth in $\mathrm{Fe}-\mathrm{Ni}-\mathrm{Zr}$ alloy below $700{ }^{\circ} \mathrm{C}$ was blocked by the interaction between the grain boundaries and zirconium solute by the solute drag affect and reduction in the grain boundary energy [22]. Above $700{ }^{\circ} \mathrm{C}$, the development of abnormal grain growth and consequent loss of thermal stability was observed by the in situ and ex situ studies. Dake and Krill [23] reported that the abnormal grain growth in binary $\mathrm{Fe}-$ Ti alloy is due to the $\alpha$-to- $\gamma$ transformation above $900{ }^{\circ} \mathrm{C}$. This phenomenon and its impact on microstructure evolution and abnormal grain growth were investigated by in situ $\mathrm{X}$-ray diffractometry for identification of the phases present during thermal annealing.

Figure 3 shows diffraction patterns obtained for $\mathrm{Fe}_{91} \mathrm{Ni}_{8} \mathrm{Zr}_{1}$ during isochoric annealing up to $900{ }^{\circ} \mathrm{C}$ for a total duration of $4 \mathrm{~h}$, such that analysis at each temperature took approximately $30 \mathrm{~min}$. A slight horizontal shift as a function of temperature was noticed in the peak positions due to thermal expansion of the lattice with increase in temperature [24]. The XRD results reveal that the microstructure remains pure bcc up to annealing to $650{ }^{\circ} \mathrm{C}$ where an fcc peak was first observed. The intensity of the fcc peak at $650{ }^{\circ} \mathrm{C}$ is substantially lower suggesting that the volume fraction of the fcc phase is very small and it is just beginning to nucleate and grow. It is worth noting that the fcc peak is much narrower than the bcc peak at and above $700{ }^{\circ} \mathrm{C}$. While the bcc peak narrows with temperature, it remains fairly wide even at $800-900{ }^{\circ} \mathrm{C}$. It indicates that even at small volume fractions the fcc grains are much larger on average than the bcc grains, implying that the large grains formed above $700{ }^{\circ} \mathrm{C}$ are fcc, while small grains detected in the microstructure are still bcc. Comparison of Figs. 1 and 2 with the data obtained from Fig. 3 suggests that the bcc to fcc phase transformation is, indeed, responsible for the rapid formation of large (fcc) grains in (bcc) nanocrystalline matrix above $700{ }^{\circ} \mathrm{C}$ and caused the loss of thermal stability. To evaluate this effect, we can estimate the driving pressure $P$ for grain growth, which determines the velocity $v$.

$v=M \cdot P=M_{o} e^{-Q / R T} \cdot P$

$M$ is the grain boundary mobility and $Q$ is the activation energy. If we assume that the grains in the nanocrystalline TEM specimen (Fig. 1) are hexagonal prisms (as in thin films) of width $D$ and thickness $h$, and define the driving force for grain boundary migration as the total free energy reduction for incremental growth $\delta \mathrm{D}$, then the driving force for an fcc $\gamma$-Fe grain growing in a surrounding bec $\alpha$-Fe grain matrix is due to the change in volume free energy $(\delta G)$, surface energy $\left(\delta \Gamma_{s}\right)$, and interphase energy-grain boundary energy $\left(\delta \Gamma_{\mathrm{i} / \mathrm{gb}}\right)$.

$$
\begin{aligned}
& \delta G=\left(g^{\gamma}-g^{\alpha}\right) \delta V=\left(g^{\gamma}-g^{\alpha}\right) \frac{3 \sqrt{3}}{2} D h \delta \mathrm{D} \\
& \delta \Gamma_{s}=\left(\Gamma_{s}^{\gamma}-\Gamma_{s}^{\alpha}\right) \delta A_{s}=\left(\Gamma_{s}^{\gamma}-\Gamma_{s}^{\alpha}\right) \frac{3 \sqrt{3}}{2} D \delta \mathrm{D} \\
& \delta \Gamma_{\mathrm{i} / \mathrm{gb}}=\left(\Gamma_{i}^{\gamma \alpha} \delta A_{\mathrm{i}}-3 h \Gamma_{\mathrm{gb}}^{\alpha} \delta \mathrm{D}\right)=\left(\Gamma_{i}^{\gamma \alpha}-\Gamma_{\mathrm{gb}}^{\alpha}\right) 3 h \delta \mathrm{D}
\end{aligned}
$$

$A_{s}$ is the free surface area, $A_{\mathrm{i}}$ is the grain interface area, $V$ is the volume of grains, $g$ is the bulk free energy per volume, $\Gamma_{s}$ is the surface energy per area, $\Gamma_{\mathrm{i}}$ is the $\alpha$-to- $\gamma$ interface energy per area, and $\Gamma_{\mathrm{gb}}$ is the grain boundary energy per area. The pressure acting on the grain interfaces will be

$P=-\frac{1}{A_{\mathrm{i}}}\left[\frac{\delta G}{\delta D}+\frac{\delta \Gamma_{s}}{\delta D}+\frac{\delta \Gamma_{\mathrm{i} / \mathrm{gb}}}{\delta D}\right]$

Combination of Eq. (2-5) will give Eq. (6) where $P>0$ will be outward and will drive grain growth. 

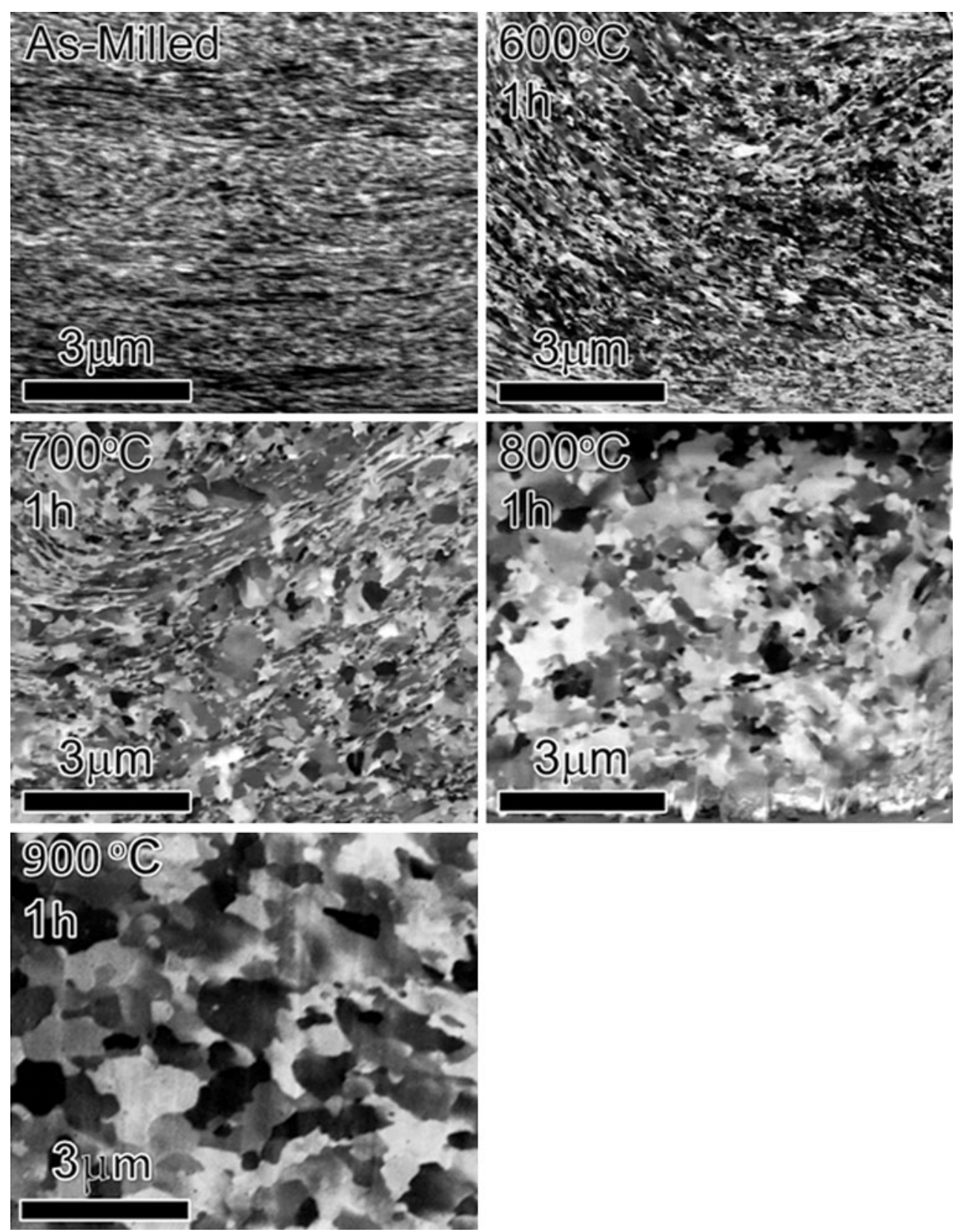

Fig. 2 Channeling contrast images of $\mathrm{Fe}_{91} \mathrm{Ni}_{8} \mathrm{Zr}_{1}$ as-milled, annealed at $600,700,800$, and $900{ }^{\circ} \mathrm{C}$. There is no significant grain growth after $1 \mathrm{~h}$ annealing at $600{ }^{\circ} \mathrm{C}$. Above $700{ }^{\circ} \mathrm{C}$, a certain fraction of

$$
\begin{aligned}
P= & -\left[\frac{1}{3 D h}\right]\left[\frac{3 \sqrt{3}}{2} D h\left(g^{\gamma}-g^{\alpha}\right)+\frac{3 \sqrt{3}}{2} D\left(\Gamma_{s}^{\gamma}-\Gamma_{s}^{\alpha}\right)\right. \\
& \left.+3 h\left(\Gamma_{\mathrm{i}}^{\gamma \alpha}-\Gamma_{\mathrm{gb}}^{\alpha}\right)\right] \\
P= & -\left[\frac{\sqrt{3}}{2}\left(g^{\gamma}-g^{\alpha}\right)+\frac{\sqrt{3}}{2 h}\left(\Gamma_{s}^{\gamma}-\Gamma_{s}^{\alpha}\right)+\frac{1}{D}\left(\Gamma_{\mathrm{i}}^{\gamma \alpha}-\Gamma_{\mathrm{gb}}^{\alpha}\right)\right]
\end{aligned}
$$

The grain boundary energy, interphase boundary energy, $\alpha$-to- $\gamma$ volume free energy change, and $\alpha$-to- $\gamma$ surface grains grow abnormally, the nanocrystalline state is lost and sudden grain growth is observed

energy change are reported to be $0.70 \mathrm{~J} / \mathrm{m}^{2}$ [25], $0.8 \mathrm{~J} / \mathrm{m}^{2}$ [26], $1230 \mathrm{~J} / \mathrm{mol}$ at $727^{\circ} \mathrm{C}$ [27], and $0.053 \mathrm{~J} / \mathrm{m}^{2}$ [26], respectively. If $\gamma=\alpha$ (before phase transformation), then the driving pressure $P=0$. If $\gamma$ grain forms in $\alpha$ matrix, it will change the pressure on grain boundaries and there will be a driving force to grow the $\gamma$ grains in the $\alpha$-grain surroundings. If we use $150 \mathrm{~nm}$ as the film thickness, the pressure for grain growth $P=+150 \mathrm{MPa}$. By comparison of in situ TEM and ex situ FIB images, it appears that surface energy in the in situ TEM sample does not affect the abnormal grain growth significantly. Moreover, the 


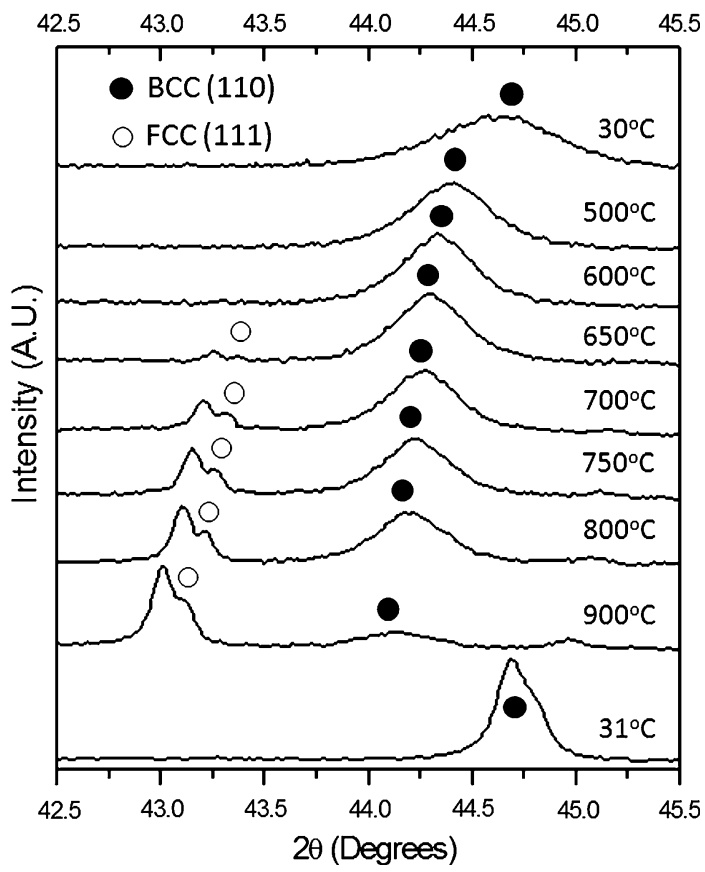

Fig. 3 In situ $\mathrm{XRD}$ scans of a $\mathrm{Fe}_{91} \mathrm{Ni}_{8} \mathrm{Zr}_{1}$ alloy during isochoric annealing from room temperature to $900{ }^{\circ} \mathrm{C}$. The first scan $30{ }^{\circ} \mathrm{C}$ is the initial microstructure showing broad bcc Fe peak. As indicated, fcc Fe peak appears around $650{ }^{\circ} \mathrm{C}$ and bcc Fe peak remains stable up to $900{ }^{\circ} \mathrm{C}$. The last scan $31{ }^{\circ} \mathrm{C}$ is after heat treatment showing the disappearance of the fcc Fe peaks and the reappearance of the bcc Fe

calculations for $P$ indicate that crucial contributions to grain growth come from the reduction in the grain boundary energy and, mostly, from the volume free energy change for $\alpha$-to- $\gamma$. This change is large $(1230 \mathrm{~J} / \mathrm{mol})$ which gives the $\gamma$ grains a significant growth advantage over $\alpha$ grains, thereby triggering sudden grain growth in abnormal manner and eventually causing loss of thermal stability. The last XRD scan at $31{ }^{\circ} \mathrm{C}$ is after heat treatment and shows the disappearance of the fcc $\gamma$ peaks and the reappearance of the bcc $\alpha$ peaks.

The bcc phase remains up to $900{ }^{\circ} \mathrm{C}$ (see Fig. 3) even though it is expected to vanish according to the $\mathrm{Fe}-\mathrm{Ni}-\mathrm{Zr}$ phase diagram [28]. It is well-known that the austenite phase nucleates at GBs, triple points or near regions in Fe-based alloys [29], and the alloying elements, such as nickel, are redistributed during the nucleation and growth of the austenite phase [30] enriching the solute atoms at some regions and depleting it in others. We propose that the initial solute distribution of $\mathrm{Ni}$ (an fcc stabilizer), locally high in some regions, will favor the nucleation and growth of austenite at temperatures near the bcc to fcc transition $\left(\sim 700{ }^{\circ} \mathrm{C}\right)$. The growth and formation of these new fcc grains as temperature increases $>700{ }^{\circ} \mathrm{C}$ will lead to the incorporation of $\mathrm{Ni}$ in higher concentrations than the average global content within or near the fcc grains. Through mass balance, the amount of nickel consumed or

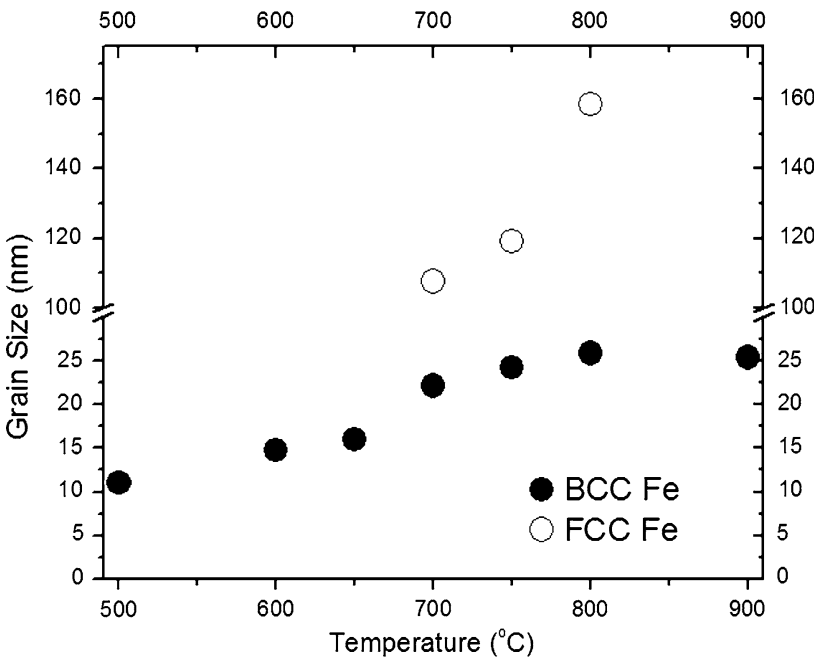

Fig. 4 Grain size analysis of the diffraction peaks shown in Fig. 3, plotted against annealing temperature for the duration of $30 \mathrm{~min}$ at each temperature. The bcc phase consists of nanoscale grains until $900{ }^{\circ} \mathrm{C}$, which grow an initial size of $10 \mathrm{~nm}$ to a final size of $25 \mathrm{~nm}$. The fcc peak was intense enough to calculate grain size at $700{ }^{\circ} \mathrm{C}$

redistributed during austenite formation and growth must also be removed or redistributed from the surrounding matrix of nanograins. The resistance to transformation by these newly depleted (lower nickel content) nanograined regions is now a function of both composition and temperature as prescribed by the $\alpha$-to- $\gamma$ equilibrium phase limits. As more austenite grains nucleate and grow, the local nickel solute content in some regions may approach zero, thereby pushing the transition temperature up to that of pure iron, $913{ }^{\circ} \mathrm{C}$, locally. The diffusivity (for $\mathrm{Fe}-10$ at $\% \mathrm{Ni}$ ) and diffusion distance calculated from Eqs. (8) and (9) were found to be $2.72 \times 10^{-14} \mathrm{~cm}^{2} / \mathrm{s}$ (based on $Q$ and $D_{o}$ values obtained from Ref. [31]) and $70 \mathrm{~nm}$, respectively, after $30 \mathrm{~min}$ annealing at $900{ }^{\circ} \mathrm{C}$.

$\tilde{D}=D_{o} \exp (-Q / R T)$

$r=\sqrt{\tilde{D} t}$

$\tilde{D}$ is the diffusivity, $D_{o}$ is the frequency factor, $Q$ is the activation energy, $r$ is the diffusion distance, $t$ is the annealing time, $T$ is the annealing temperature, and $R$ is the gas constant. This suggests that nickel atoms had the opportunity during thermal annealing to be redistributed over length scales approximately equal to or larger than the grain size within the retained nanocrystalline regions. This implies that the small grains observed at 800 -and $900{ }^{\circ} \mathrm{C}$ in the FIB images in Fig. 2 are bcc $\alpha$ grains which never transformed to or were consumed by fcc $\gamma$ grains during thermal annealing.

Figure 4 shows the Scherrer grain size analysis of the diffraction peaks reported in Fig. 3. It reveals that the grains of the bcc phase grow from an initial size of $10 \mathrm{~nm}$ 
to a final size of $25 \mathrm{~nm}$ after $30 \mathrm{~min}$ annealing at $900{ }^{\circ} \mathrm{C}$ (for a total duration of $4 \mathrm{~h}$ ). The fcc phase appears at $650{ }^{\circ} \mathrm{C}$, but the corresponding diffraction peak is not intense enough to allow calculation of the grain size. The estimated grain size of the fcc phase was approximately $105 \mathrm{~nm}$ at $700{ }^{\circ} \mathrm{C}$, and proceeded to increase with increasing annealing temperature.

\section{Conclusions}

The observations from in situ and ex situ experiments reported above and the information obtained from these studies enable us to understand the grain growth in stabilized Fe-Ni-based alloys. From our observations, it is suggested that the microstructural evolution is fairly slow and the microstructure shows a solid stabilization up to about $700{ }^{\circ} \mathrm{C}$. This is attributed to zirconium segregation to grain boundaries and the solute drag effect. Above $700{ }^{\circ} \mathrm{C}$, the grain growth kinetics becomes extremely fast, especially for the first few seconds of annealing and causes a sudden grain growth in abnormal manner. The reasons for abnormal grain growth and the loss of thermal stability were identified as the appearance of the fcc $\gamma$ phase and consequent reduction in the total area of grain boundaries and the overall stored energy in the sample.

Acknowledgements The research reported in this paper was supported by NSF-DMR under grant number 1005677.

\section{References}

1. Gleiter H (1989) Prog Mater Sci 33(4):223

2. Birringer R (1989) Mater Sci Eng A 117:33

3. Suryanarayana C (2002) Jom-J Min Metals Mater Soc 54(9):24

4. Koch CC, Scattergood RO, Darling KA, Semones JE (2008) J Mater Sci 43(23-24):7264
5. Koch CC (2007) J Mater Sci 42(5):1403

6. Suryanarayana C (1995) Int Mater Rev 40(2):41

7. Gleiter H (1992) Adv Mater 4(7-8):474

8. VanLeeuwen BK, Darling KA, Koch CC, Scattergood RO, Butler BG (2010) Acta Mater 58(12):4292

9. Krill CE, Ehrhardt H, Birringer R (2005) Zeitschrift Fur Metallkunde 96(10):1134

10. Shaw L, Luo H, Villegas J, Miracle D (2003) Acta Mater 51(9):2647

11. Frolov T, Darling KA, Kecskes LJ, Mishin Y (2012) Acta Mater 60(5):2158

12. Darling KA, VanLeeuwen BK, Koch CC, Scattergood RO (2010) Mater Sci Eng, A 527(15):3572

13. Perez RJ, Jiang HG, Dogan CP, Lavernia EJ (1998) Metall Mater Transac A 29(10):2469

14. Kirchheim R (2007) Acta Mater 55(15):5129

15. Michels A, Krill CE, Ehrhardt H, Birringer R, Wu DT (1999) Acta Mater 47(7):2143

16. www.protochips.com

17. Smith CJE, Dillamore IL (1970) Metal Sci 4(1):161

18. Kotan H, Saber M, Koch CC, Scattergood RO (2012) Mater Sci Eng, A 552:310

19. Darling KA, VanLeeuwen BK, Semones JE, Koch CC, Scattergood RO, Kecskes LJ, Mathaudhu SN (2011) Mater Sci Eng, A 528(13-14):4365

20. Shen TD, Schwarz RB, Feng S, Swadener JG, Huang JY, Tang M, Zhang H, Vogel SC, Zhao YS (2007) Acta Mater 55(15):5007

21. Malow TR, Koch CC (1997) Acta Mater 45(5):2177

22. Kotan H, Darling KA, Saber M, Koch CC, Scattergood RO (2012) J Alloys Comp. doi:10.1016/j.jallcom.2012.10.179

23. Dake JM, Krill CE (2012) Scripta Mater 66(6):390

24. Culity BD (1977) Element of X-ray diffraction, 2nd edn. Addison-Wesley, MA

25. Murr LE (1975) Interfacial phenomena in metals and alloys. Addision-Wesley, MA

26. Yang Z, Johnson RA (1993) Modell Simul Mater Sci Eng 1(5):707

27. Kubaschewski O, Goldbeck OV (1949) Trans Faraday Soc 45:948

28. Raghavan V (1992) Indian Inst Metals 6B:1094

29. Syn CK, Jin S, Morris JW (1976) Metall Transac A 7:1827

30. Mun SH, Watanabe M, Li X, Oh KH, Williams DB, Lee HC (2002) Metall Mater Transac A 33:1057

31. Askil J (1970) Tracer diffusion data for metals, alloys and simple oxides. Plenum Publishing Corporation, NY 